\title{
The association of adiponectin gene polymorphisms with susceptibility and progression of NAFLD in a cohort of Egyptian patients
}

\author{
Eman M. Hasan ${ }^{1}$, Rasha A. Abd Al Aziz , Dina Sabry², Hedy A. Badary ${ }^{1}$, Yasmine Gaber $^{1}$, Ayman Yosry ${ }^{1}$ and
} Zeinab Zakaria ${ }^{1 *}$ (D)

\begin{abstract}
Background: Several genetic polymorphisms have been proven to play a key role in the progression of nonalcoholic fatty liver disease (NAFLD) from simple steatosis to NASH with fibrosis. Our aim was to study the effect of single nucleotide polymorphisms (SNPs) in the adiponectin gene, namely rs266729 and rs3774261, on susceptibility to NAFLD and disease progression.

Results: There was a definitive association between polymorphisms of the studied SNPs and NAFLD. Among rs266729, CG was significantly higher among patients than controls showing increased risk for NAFLD $(P<0.05)$. AA genotype of the rs3774261 variant was significantly lower in patients than in controls ( $P$ value $<0.001$ ) while $A G$ and GG genotypes were significantly higher in patients than in controls ( $P$ value $<0.05$ ); A allele was significantly higher among controls $(P=0.019)$ which might have a protective effect. None of the variants correlated significantly with the degree of steatosis. Using multivariate regression analysis, there was no significant correlation with any of the independent risk factors to the degree of steatosis.
\end{abstract}

Conclusions: There was an association between polymorphisms of the studied SNPs of rs266729 and rs3774261 of the adiponectin gene and NAFLD.

Keywords: NAFLD, NASH, SNPs, Adiponectin gene, CAP

\section{Background}

Non-alcoholic fatty liver disease (NAFLD) is rapidly becoming the most common liver disease worldwide [1]. The prognosis and outcome of these patients are mainly determined by the liver fibrosis severity. Accordingly, precise differentiation between NASH and NAFL so as to define the best treatment is needed [2]. Excess visceral fat and waist circumference are considered the main risk factors for NAFLD and are closely related to disease severity [3].

\footnotetext{
* Correspondence: zenab.zakaria@yahoo.com

${ }^{1}$ Department of Endemic Medicine and Hepato-Gastroenterology, Faculty of Medicine, Cairo University, Cairo, Egypt

Full list of author information is available at the end of the article
}

Considering that liver biopsy is the diagnostic gold standard of NAFLD, however, it is an invasive procedure with potential risks or complications. Thus, different non-invasive diagnostic tests have been suggested as alternatives to liver biopsy [4]. Among these tests, the controlled attenuation parameter (CAP) has been developed to assess liver steatosis. CAP is measured using the FibroScan (Echosens ${ }^{\circ}$, Paris, France), which is based on vibration-controlled transient elastography (VCTE), a technique initially developed to assess liver stiffness (LS), which is highly correlated with liver fibrosis [5].

The study of genetic factors in NAFLD is a rapidly growing field [6]. Salman et al. and Jamali et al. have demonstrated the association of NAFLD and its severity 
with the levels of serum adipokines, a group of bioactive proteins secreted by adipose tissue and having actions on inflammation and insulin resistance [7, 8]. Several studies have indicated that adiponectin is protective against NAFLD [9]. The aim of this study was to investigate the association between two SNPs of adiponectin gene, namely rs266729 and rs3774261, and NAFLD as well as the impact of multiple SNP interaction on NAFL $\mathrm{D}$ risk based on an Egyptian population study, and its relation to the degree of hepatic steatosis as assessed by controlled attenuation parameter.

\section{Methods}

The present study included 86 Egyptian patients, prospectively selected from the hepatology outpatient clinic of Kasr Al-Ainy Hospital over a period of 12 months (from February 2017 to February 2018), who were suspected to have NAFLD according to the following inclusion and exclusion criteria, in addition to 86 agematched healthy subjects serving as a control group. The patients were further subdivided into (1) the biopsy group (17 patients) and (2) the non-biopsy group (69 patients). All participants aged above 18 years, and all patients were suspected to have NAFLD on the basis of increased hepatic brightness by abdominal ultrasound with the exclusion of other causes of secondary steatosis such as negative viral markers ( $\mathrm{HCV} \mathrm{Ab}, \mathrm{HBsAg}, \mathrm{HBc}$ total), negative ANA, transferrin saturation $<45 \%$ coupled with normal ferritin levels, normal serum levels of ceruloplasmin, and negative history for significant alcohol consumption (>20 g/d for females and $30 \mathrm{~g} / \mathrm{d}$ for males) and for use of medications that can cause fatty liver.

All participants were interviewed for their medical history, and their residence was classified into urban or rural areas based on the infrastructure and the available services [10]. The BMI was calculated as body weight in kilograms divided by height in square meters $\left(\mathrm{kg} / \mathrm{m}^{2}\right)$. Zheng et al. evaluated waist to hip ratio (WHR) as a predictor of NAFLD with a cutoff point of 0.89 [11], whereas in the present study, we applied the waist circumference that was measured midway between the last rib margin and the iliac crest in a standing position. In order to diagnose metabolic syndrome [12], blood samples were obtained from each participant after a fasting period of at least $12-14 \mathrm{~h}$ for lipid profile. The blood glucose level was measured using the glucose oxidase method. A fasting blood sugar level from 100 to 125 $\mathrm{mg} / \mathrm{dl}$ is considered impaired fasting glucose and 126 $\mathrm{mg} / \mathrm{dl}$ or higher is considered diabetes [12]. Serum total cholesterol, HDL cholesterol, LDL cholesterol, and triglyceride levels were measured on an auto-analyzer using enzymatic calorimetry, and hypertriglyceridemia is considered when triglycerides $\geq 150 \mathrm{mg} / \mathrm{dL}$ [12]. Serum levels of ALT, AST, GGT, alkaline phosphatase, and albumin, as well as serum ferritin and ceruloplasmin, were measured. HBsAg, HBc total, HCV Ab, ANA were measured using ELISA. Polymerase chain reaction restriction fragment length polymorphism (PCR-RFLP) was applied to detect the distribution of genetic polymorphisms of the adiponectin gene. Transabdominal ultrasonography used a Toshiba SSA-340A machine with a 3.5-MHz convex linear transducer. Ultrasonography-guided liver biopsy was done for only 17 of the patients (the biopsy group), and scoring used the NAS scoring system according to the Histological Scoring System for NAFLD and used Masson trichrome stain for assessing the degree of fibrosis [13]. Fibrosis staging was evaluated (separately from $\mathrm{NASH}$ ) from 0 to 4 scales. The hepatic steatosis was graded from 0 to 3 based on the number of hepatocytes with steatosis in the biopsy: S0, <5\%; S1, 533\%; S2, 34-66\%; and S3, >66\% [14]. Controlled attenuated parameter (CAP) was performed for all patients and controls using the $3.5-\mathrm{MHz} \mathrm{M}$ probe of Echosens FibroScan $^{\oplus}$. Liver stiffness measurement (LSM) was performed for all patients using Echosens FibroScan

\section{Measurement of LSM and CAP}

The LSM was expressed as $\mathrm{kPa}$, and the examination was considered reliable if 10 valid LSMs were obtained, the success rate exceeded $60 \%$, and the ratio of the interquartile range (IQR) to the median of 10 measurements (IQR/M) was 0.3.

CAP measures the ultrasound attenuation (go and return path) using signals acquired by either the $3.5-\mathrm{MHz}$ or $2.5-\mathrm{MHz}$ FibroScan probe. The final CAP value, which ranges from 100 to $400 \mathrm{~dB} / \mathrm{m}$, is the median of individual measurements. As an indicator of variability, the ratio of the IQR of CAP values to the median (IQR/ MCAP) was calculated. The operator was blinded to the patients' clinical and histological data.

\section{Detection of adiponectin gene polymorphisms Blood samples collection}

Five milliliters of whole blood sample was collected from each patient. The whole blood was subjected to DNA extraction and followed by further assessment of adiponectin polymorphisms rs266729 and rs3774261 by restriction fragment length polymorphism polymerase chain reaction (RFLP-PCR).

\section{RFLP-PCR procedure for adiponectin polymorphism diagnosis DNA extraction}

All samples were in the form of frozen whole blood and were processed using the Zymoresearch Quick-gDNA ${ }^{\text {тм }}$ MiniPrep kit, Catalog No. D3024 (available online at 
http://www.zymoresearch.com/downloads/dl/file/id/18/ d3006i.pdf), through Epigenetics Company.

The following steps were applied on all blood samples.

(1) For the preparation of the Genomic Lysis Buffer, $250 \mu \mathrm{l}$ of beta-mercaptoethanol was added to $50 \mathrm{ml}$ of the buffer. (2) One hundred microliters of blood was added to $400 \mu \mathrm{l}$ of Genomic Lysis Buffer. (3) They were mixed together completely by vortexing for $4-6$ s. (4) The mixture was let stand $5-10 \mathrm{~min}$ at room temperature. (5) The mixture was transferred to a Zymo-Spin $^{\text {tw }}$ Column in a collection tube and centrifuged at $10,000 \times g$ for $1 \mathrm{~min}$, and the collection tube was discarded with the flow-through. (6) The Zymo-Spin ${ }^{\text {nu }}$ Column was transferred to a new collection tube, and $200 \mu \mathrm{l}$ of DNA Pre-Wash Buffer was added to the spin column and centrifuged at 10,000 $\mathrm{x}$ g for $1 \mathrm{~min}$. 7. 500 $\mu \mathrm{l}$ of g-DNA Wash Buffer was added to the spin column and then centrifuged at $10,000 \times g$ for $1 \mathrm{~min}$. (8) The spin column was transferred to a clean microcentrifuge tube, then $60 \mu \mathrm{l}$ of DNA Elution Buffer was added to the spin column. (9) It was incubated $2-5 \mathrm{~min}$ at room temperature and then centrifuged at top speed for $30 \mathrm{~s}$ to elute the DNA. (10) The eluted DNA was stored at $-20^{\circ} \mathrm{C}$ for future use.

\section{Real-time PCR}

This step involved DNA amplification and detection of the studied SNPs using Real MODTM Real-time PCR Master Mix (Intron Biotechnology, Catalog no. 25341; available online at http://eshop.intronbio.com/product/ detail04.asp?pIdx=89\#).

\section{Quantification of DNA}

The concentration of DNA was determined by measuring the absorbance at $260 \mathrm{~nm}$ (A260) using the Nanodrop ND-1000* spectrophotometer. Distilled water was used to zero the spectrophotometer. The concentration is displayed in $\mathrm{ng} / \mu \mathrm{l}$. The recommended DNA template concentration for TaqMan SNP Genotyping Assay is 1$20 \mathrm{ng} / \mu \mathrm{l}$. During the present assay, $20 \mathrm{ng}$ was the goal, and the volume was adjusted accordingly.

\section{Steps}

The reaction mixture was prepared according to the following: $10 \mu \mathrm{l}$ for $2 \mathrm{x}$ RealMODTM Real-time PCR Master Mix Solution, $2 \mu \mathrm{l}$ for primers (forward+ reverse) + TaqMan $^{\circ}$ probe, $1 \mu \mathrm{l}$ for template, and DNA $7 \mu \mathrm{l}$ for RNAse-free water. The mixture was mixed thoroughly and appropriate volumes were aliquoted into the realtime PCR plates. The real-time PCR instrument (Applied Biosystems (StepOne System. SDS software v2.1 and RQ Manager 1.2)) was programmed. The real-time PCR plate was placed in the real-time PCR instrument, and the cycling program was started. After the reaction has been completed, the amplification curve was verified.

\section{Statistical analysis}

Data were coded and entered using the statistical package SPSS (Statistical Package for the Social Sciences) version 23. The data was summarized using median, minimum and maximum in quantitative data, and frequency (count) and relative frequency (percentage) for categorical data. Comparisons between quantitative variables were done using the non-parametric KruskalWallis and Mann-Whitney tests [15].

For comparing the categorical data, the chi-square test was performed. The exact test was used instead when the expected frequency is less than 5. Genotype and allele frequencies were compared between every 2 groups using chi-square tests [16].

Odds ratio (OR) with 95\% confidence intervals was calculated. Multivariate logistic regression analysis was done to detect the independent predictors of NAFLD. $P$ values less than 0.05 were considered as statistically significant.

Tests of normality of distribution of genetics (Hardy Winderberg) in controls (86 samples) were performed. The likelihoods of calculated $X^{2}$ value are in Table 1 . For the rs266729, SNP $X^{2}=2.6, \mathrm{p}$ allele frequency $=$ 0.732 , and q allele frequency $=0.267$. For the rs3774261, SNP $X^{2}=43$, p allele frequency $=0.674$, and q allele frequency $=0.326$.

\section{Results}

The age of the studied patients ranged from 25 to 67 years $(44.3 \pm 9.45$ years), out of which $65.2 \%$ were females and $34.8 \%$ were males. BMI ranged from 23.3 to $50.3 \mathrm{~kg} / \mathrm{m}^{2}\left(33.76 \pm 5.436 \mathrm{~kg} / \mathrm{m}^{2}\right)$, whereas the waist circumference (WC) was about $107.3 \pm 11.66 \mathrm{~cm}$. On the other hand, among the control group, ages ranged from 20 to 63 years $(38.67 \pm 8.854$ years), $33.7 \%$ were females and $66.3 \%$ were males, BMI was $25.65 \pm 1.623 \mathrm{~kg} / \mathrm{m}^{2}$, and WC was $81.38 \pm 5.363 \mathrm{~cm}$.

According to the BMI, patients and controls were categorized into normal $\left(18.5-24.9 \mathrm{~kg} / \mathrm{m}^{2}\right)$, overweight $\left(25.0-29.9 \mathrm{~kg} / \mathrm{m}^{2}\right)$, obese $\left(30.0-40.0 \mathrm{~kg} / \mathrm{m}^{2}\right)$, and

Table 1 Likelihood of calculated $X^{2}$ value for test of normality of distribution of genetics in controls

\begin{tabular}{llll}
\hline & & Expected & Observed \\
\hline rs266729 & CC & 46.1 & 44 \\
& CG & 33.6 & 38 \\
rs3774261 & GG & 6.1 & 4 \\
& AA & 78.14 & 39 \\
& AG & 75.59 & 38 \\
& GG & 18.28 & 9 \\
\hline
\end{tabular}


morbidly obese $\left(>40.0 \mathrm{~kg} / \mathrm{m}^{2}\right)$. Among patients, 17 (19.8\%) were overweight, 57 (66.3\%) were obese, and 10 (11.6\%) were morbidly obese, whereas among controls, 32 (37.2\%) were within normal BMI, 53 (62.6\%) were overweight, and $1(1.2 \%)$ was obese, while none was morbidly obese.

BMI distribution was determined in patients according to their age as follows: in young adults (25-30 years), $33.3 \%$ were overweight, $33.3 \%$ were obese, and $33.3 \%$ were morbidly obese; in adults (31-40 years), $0 \%$ were overweight, $25.9 \%$ were obese, and $74.1 \%$ were morbidly obese; in middle-aged patients ( $40-50$ years), $0 \%$ were overweight, $17.2 \%$ were obese, and $58.7 \%$ were morbidly obese; in the older age (50-60 years and 60-66 years) patients, none were overweight, $13.6 \%$ and $0 \%$ were obese, and $72.5 \%$ and $100 \%$ were morbidly obese, respectively.

Among patients and controls, $47.7 \%$ and $24.4 \%$ were housewives, $2.3 \%$ and $3.5 \%$ were unemployed, while $14 \%$ and $46.5 \%$ had labor-intensive occupations (workers, mechanics, and farmers), respectively. The rest occupied jobs with a more clerical nature. According to the governorate of residence, the largest number of patients and controls were living in urban areas accounting for $74.4 \%$ and $81.4 \%$ among patients and controls, respectively

Among known risk factors for the development of NAFLD, increased BMI was found in almost all except two patients $(2.3 \%)$ with NAFLD, $19.8 \%$ were overweight, $66.3 \%$ were obese, and $11.6 \%$ were morbidly obese, whereas in the control group, $37.2 \%$ were normal, $61.6 \%$ were overweight, only one subject $(1.2 \%)$ was obese, and none were morbidly obese $(P<0.01)$.

As regards the presence of diabetes mellitus among patients versus controls, $27.9 \%$ had DM, as opposed to $2.3 \%$ of the controls $(P<0.01)$, whereas systemic hypertension was found in $15.1 \%$ in the patient group and in $0 \%$ (none) of the control group. None of the control subjects had a family history of NAFLD; however, 25.6\% of the patient group had a family history of NAFLD in at least one first-degree relative.

Metabolic syndrome is defined by the presence of three of the following five criteria: fasting glucose $\geq 100 \mathrm{mg} / \mathrm{dL}$ (or receiving drug therapy for hyperglycemia), blood pressure $\geq 130 / 85 \mathrm{mmHg}$ (or receiving drug therapy for hypertension), triglycerides $\geq 150 \mathrm{mg} / \mathrm{dL}$ (or receiving drug therapy for hypertriglyceridemia), HDL-C $<40 \mathrm{mg} / \mathrm{dL}$ in men or $<50 \mathrm{mg} / \mathrm{dL}$ in women (or receiving drug therapy for reduced HDL-C), and waist circumference $\geq 102 \mathrm{~cm}$ in men or $\geq 88 \mathrm{~cm}$ in women. Metabolic syndrome was identifiable in $19.8 \%$ as opposed to $0 \%$ of the controls $(P<0.01)$.

Smoking was present among $13.9 \%$ and $11.6 \%$ of patients and controls, respectively, whereas $1.16 \%$ (1 patient) was identified as an ex-smoker. None of the patients or the controls gave a history of heavy alcohol consumption or of drug abuse.
Serum lipid abnormalities in the form of elevated total cholesterol, triglycerides, and low-density lipoprotein cholesterol (LDL-c) levels, and reduced serum highdensity lipoprotein cholesterol (HDL-c) levels were significantly detected in the patient group as opposed to the control group $(P<0.0001)$. Moreover, serum fasting and post-prandial blood sugar were significantly higher in the patient group as opposed to the control group ( $P$ $<0.0001)$. Hemoglobin A1C results, however, showed no significant difference among patients versus controls $(P=$ 0.85).

None of the patients had abnormal thyroid function profiles; however, ten gave a history of hypothyroidism for which they receive ongoing treatment in the form of L-thyroxin tablets. None of the patients had abnormal serum ferritin levels.

Among patients, the most common complaints were right upper quadrant pain, occurring in 41 patients (47.7\%), and abdominal discomfort, occurring in 21 patients $(24.4 \%)$, followed by fatigue in 20 patients $(23.3 \%)$, and lower limb edema and history of IHD in 2 patients (2.3\%) and 3 patients (3.5\%), respectively. Among the control group, no complaints were reported.

By physical examination, mild hepatomegaly was detected in 6 patients (7\%), out of which 3 had tender hepatomegaly (3.5\%). In all of these patients, the liver was felt soft in consistency, with a round edge. Only one of the patients had a palpable spleen (1.2\%). Otherwise, physical examination among both patients and controls was unremarkable. None of the patients or the controls showed signs suggestive of liver cell failure in the form of jaundice, ascites associated with lower limb edema, or disturbed level of consciousness.

As regards laboratory data of the studied groups, serum transaminases, were found to be higher in the patients' group as opposed to the control group $(P<$ $0.0001)$. Noteworthy, $48.8 \%(42 / 86)$ of the patients had serum hepatic transaminases below the upper limit of normal.

Using trans-abdominal ultrasonography in assessing the hepatic echogenicity, control subjects showed normal hepatic echogenicity. Whereas liver brightness was graded into grades I, II, and III among patients as follows: grade I brightness was diagnosed in 18 patients (20.9\%), grade II brightness was diagnosed in 37 patients (43.0\%), and grade III brightness was diagnosed in 31 patients (36.1\%).

Among the 17 patients who underwent liver biopsy, according to histopathological findings (degree of steatosis, degree of inflammation, presence of ballooning) and NAS score, NAFLD was classified into 2 subgroups (simple steatosis and NASH) with their histopathological features using the NAS Score, with a cutoff value of $\geq 5$, 4 patients were identified as having NAFL, whereas 13 had biopsy-proven steatohepatitis (Table 2). 
No significant relation was found between grades of steatosis by liver biopsy and presence or absence of NASH by (NAS) score where between 13 biopsy-proven NASH patients, $5(38.5 \%)$ and $8(61.5 \%)$ had histological evidence of moderate and marked hepatic steatosis. On the other hand, among 4 patients with simple steatosis, 2 (50\%) had mild steatosis, and 2 (50\%) had moderate steatosis.

As regards the level of steatosis detected by CAP and biopsy results, among the biopsy group, two patients (11.8\%) who had biopsy-proven mild steatosis (S1), when further assessed by controlled attenuation parameter, showed marked steatosis (S3) (16.6\%). Out of the 7 patients (41.2\%) with biopsy-proven moderate (S2), 6 (85.7\%) showed S2, and only one (14.3\%) showed S3 upon further assessment by CAP, and out of the 8 $(47.0 \%)$ who biopsy-proven severe (S3) steatosis, 7 (87.5\%) showed S3, and 1 (12.5\%) S2 when further assessed by CAP (Table 3).

Upon further evaluation of the biopsy group, the degree of fibrosis detected by biopsy was not significantly related to the fibrosis stage (F0-4) detected by FibroScan $\left(\right.$ Echosenes $\left.^{\odot}\right)$. There was no significant relation between the degree of steatosis detected by CAP and the biopsyproven fibrosis stage (Table 4).

Among all studied patient groups, the degree of steatosis when measured using CAP was mild (S1) in 19.8\% (17 patients), moderate (S2) in 39.5\% (34 patients), and severe in $40.7 \%$ (35 patients), whereas the degree of fibrosis was mild (F0, F1) in 80.2\% (61 patients with F0, 8 patients $\mathrm{F} 1$ ), moderate (F2) in $10.5 \%$ (9 patients), and marked (F3-4) in 7\% (6 patients) and 2.3\% (2 patients) using FibroScan (Echosens ${ }^{\oplus}$ ), respectively.

The degree of steatosis by CAP when compared to the grades of brightness by trans-abdominal US, we found that the different grades of brightness by transabdominal ultrasonography showed significant relation with the degree of steatosis measured utilizing CAP with a $P$ value $<0.001$.

As regards the relation between the degree of steatosis detected by CAP and different clinical parameters, the degree of moderate and advanced steatosis was higher among females than among males in advanced steatosis (68.6\% vs $31.4 \%$ and $68.8 \%$ vs. $31.4 \%$, respectively),

Table 3 The relation between biopsy-proven steatosis and CAP

\begin{tabular}{|c|c|c|c|c|c|c|c|c|}
\hline & & \multicolumn{6}{|c|}{ Biopsy proven steatosis } & \multirow{3}{*}{$\begin{array}{l}P \\
\text { value }\end{array}$} \\
\hline & & \multicolumn{2}{|l|}{ S1 } & \multicolumn{2}{|l|}{ S2 } & \multicolumn{2}{|l|}{ S3 } & \\
\hline & & Count & $\%$ & Count & Count & $\%$ & Count & \\
\hline \multirow[t]{4}{*}{ CAP (S0-S3) } & so & 0 & 0 & 0 & 0 & 0 & 0 & $<0.001$ \\
\hline & S1 & 0 & 0 & 0 & 0 & 0 & 0 & \\
\hline & S2 & 0 & 0 & 6 & 85.7 & 1 & 12.5 & \\
\hline & S3 & 2 & 100 & 1 & 14.29 & 7 & 87.5 & \\
\hline
\end{tabular}

which was not significant statistically $(P=0.318)$. WC and BMI significantly related with the different degrees of steatosis measured by CAP. The degree of steatosis detected by CAP was associated with higher serum TGs, but it was not a significant relation (Table 5).

The distribution of rs266729 adiponectin C and G allele genotype among patients and controls showed that CG genotype was significantly related to the presence of NAFLD $(P=0.032)$, while CC genotype was significantly related to controls $(P=0.003)$, whereas rs3774261 adiponectin A and $G$ alleles showed that AG genotype was the most frequent genotype in patients with NAFLD/ 963.9\%, while AA genotype was the most frequent genotype in controls (45.3\%) (Table 6).

No significant relation was found between any of the variants of both genotypes and the degrees of both steatosis and fibrosis detected by CAP and FibroScan Echosens respectively, nor with any of the significant clinical and lab parameters (Table 7).

No significant correlation was found between ALT and AST relative to BMI or waist circumference (Table 8).

By studying the adiponectin genotype, CAP, and different metabolic parameters in relation to obesity and its degree, we found that the severity of steatosis, BMI, waist circumference, fasting blood glucose, and AST was significantly higher among obese and related to the degree of obesity at $P<0.0001$ (Table 9).

The relationship between the studied SNPs showed no statistically significant relation between rs266729 and rs3774261. Multivariate regression analysis showed no significant relation between the degree of steatosis detected by CAP and any of the independent risk factors including BMI, waist circumference, TGs, sex, rs266729, and rs3774261.

\section{Discussion}

Previous studies have shown the association of NAFLD and its severity with the levels of serum adipokines, considering adiponectin a protective protein against NAFLD [7-9]. Moreover, the recent genetic study of steatosis showed associations between single-nucleotide polymorphisms (SNPs) and disease phenotypes, which could be helpful in the management and prognosis of patients with NAFLD [17].

The aim of this study was to investigate the association between two SNPs of adiponectin genes rs266729 and rs3774261, and NAFLD as well as the impact of multiple SNP interaction on NAFLD risk based on an Egyptian population study and its relation to the degree of hepatic steatosis as assessed by controlled attenuation parameter.

In our study, gender distribution showed a female predominance $(65.2 \%)$. Similar findings were found by [18, 19]. While many studies have indicated that NAFLD is more common in men $[20,21]$, in our study, the higher 
Table 2 Liver biopsy findings among the biopsy group of patients

\begin{tabular}{|c|c|c|c|c|c|c|}
\hline & & \multicolumn{2}{|c|}{ NASH } & \multicolumn{2}{|c|}{ Simple steatosis } & \multirow{2}{*}{$\begin{array}{l}P \\
\text { value }\end{array}$} \\
\hline & & $\%$ & Count & $\%$ & Count & \\
\hline \multirow[t]{4}{*}{ Steatosis } & No grade 0 & 0 & .0 & 0 & .0 & 0.5751 \\
\hline & Mild grade 1 & 0 & .0 & 2 & 50 & \\
\hline & Moderate grade 2 & 5 & 38.5 & 2 & 50 & \\
\hline & Marked grade 3 & 8 & 61.5 & 0 & .0 & \\
\hline \multirow[t]{2}{*}{ Inflammation } & Mild & 4 & 30.8 & 4 & 100.0 & 0.9296 \\
\hline & Moderate & 9 & 69.2 & 0 & .0 & \\
\hline \multirow[t]{2}{*}{ Ballooning } & Focal & 0 & .0 & 1 & 25 & 0.074 \\
\hline & Diffuse & 13 & 100 & 3 & 75 & \\
\hline \multirow[t]{4}{*}{ Fibrosis } & Minimal & 0 & 4.5 & 0 & .0 & 0.152 \\
\hline & Mild & 4 & 30.8 & 2 & 50 & \\
\hline & Moderate & 5 & 38.4 & 2 & 50 & \\
\hline & Severe & 4 & 30.8 & 0 & .0 & \\
\hline
\end{tabular}

prevalence among females could be attributed to the fact that the prevalence of central obesity is higher among Egyptian females than males [22, 23].

As regards age, the prevalence of NAFLD was significantly increased with age $(P<0.0001)$. The degree of steatosis detected by CAP was higher among older patients, although it did not show a statistical significance. These results were supported by previous studies [1].

Obesity is closely associated with the increased prevalence and severity of NAFLD. Obesity induced steatosis causing insulin resistance by activating NF$\mathrm{kB}$ that induces proinflammatory cytokines resulting in insulin resistance [24]. The body mass index and waist circumference in our study were proved to be significantly higher in NAFLD cases than in normal controls. Moreover, the degree of obesity significantly related to the presence of hepatic steatosis. These findings were compatible with the findings of previous studies [25]. Other studies, however, concluded that NAFLD can occur in non-obese subjects who are physically inactive [26].
In this study, the prevalence of diabetes mellitus was significantly higher in NAFLD patients (27.9\%) compared to normal controls (2.3\%). This finding was in agreement with previous studies, which concluded that diabetes mellitus is an independent risk factor for the progression of NAFLD $[1,25]$.

As regards metabolic syndrome, in the present study, the prevalence of MS was significantly higher among NAFLD patients (19.8\%) compared to the control group $(0.0 \%)$ at a $P$ value $<0.001$. Previous studies reached similar conclusions, whereas NAFLD is presently considered the hepatic manifestation of MS [1, 27].

The present study validated the documented facts whereas elevated serum total cholesterol, LDL-c, and triglyceride levels, as well as reduced HDL-c levels, were found to be significantly related to the presence of NAFLD $(P \leq 0.001)$. Furthermore, higher serum levels of triglycerides and LDL-c were shown to have a relation with the different degrees of steatosis detected by CAP, but it was not a significant relation $(P=0.088$ and 0.79 , respectively).

Table 4 Relation between biopsy-proven fibrosis stage and TE and CAP results

\begin{tabular}{|c|c|c|c|c|c|c|c|c|c|c|}
\hline & & \multicolumn{8}{|c|}{ Fibrosis stage } & \multirow{3}{*}{$\begin{array}{l}P \\
\text { value }\end{array}$} \\
\hline & & \multicolumn{2}{|l|}{$4 / 4$} & \multicolumn{2}{|l|}{$3 / 4$} & \multicolumn{2}{|l|}{$2 / 4$} & \multicolumn{2}{|l|}{$1 / 4$} & \\
\hline & & Count & $\%$ & Count & $\%$ & Count & $\%$ & Count & $\%$ & \\
\hline \multirow[t]{4}{*}{ FibroScan (Echosens) } & Fo & 3 & 50.0 & 0 & .0 & 0 & .0 & 0 & .0 & 0.5884 \\
\hline & $\mathrm{F} 1$ & 3 & 50.0 & 1 & 14.3 & 0 & .0 & 0 & .0 & \\
\hline & F3 & 0 & .0 & 6 & 85.7 & 2 & 100 & 0 & .0 & \\
\hline & F4 & 0 & .0 & 0 & .0 & 0 & .0 & 2 & 100 & \\
\hline \multirow[t]{4}{*}{ CAP S(0-3) } & So & 0 & .0 & 0 & .0 & 0 & .0 & 0 & .0 & 0.6751 \\
\hline & S1 & 0 & .0 & 5 & 71.4 & 0 & .0 & 0 & .0 & \\
\hline & S2 & 1 & 16.7 & 2 & 28.6 & 1 & 50.0 & 0 & .0 & \\
\hline & S3 & 5 & 83.3 & 0 & .0 & 1 & 50.0 & 2 & 100.0 & \\
\hline
\end{tabular}


Table 5 Relation between degree of steatosis detected by CAP and various clinical and laboratory parameters

\begin{tabular}{|c|c|c|c|c|c|c|c|}
\hline & S1 & & S2 & & S3 & & $P$ \\
\hline & Mean & SD & Mean & SD & Mean & SD & \\
\hline Age & 39.75 & 7.452 & 45.63 & 9.353 & 45.06 & 9.956 & 0.1004 \\
\hline Waist circumference & 100.6 & 11.69 & 107.8 & 11.29 & 109.9 & 11.13 & $0.0282^{*}$ \\
\hline BMl & 30.55 & 4.839 & 33.92 & 4.939 & 35.07 & 5.701 & $0.0200^{*}$ \\
\hline Blood pressure & $118-72$ & 8.6 & $121-7$ & 12.10 & $119-74$ & 12.11 & 0.5 \\
\hline Fasting glucose & 93 & 22 & 92 & 19 & 104 & 36 & 0.16 \\
\hline ALT & 39.43 & 26.22 & 48.06 & 36.16 & 38.71 & 24.28 & 0.5445 \\
\hline $\mathrm{HDL}$ & 41.69 & 9.192 & 52.59 & 36.26 & 44.19 & 13.28 & 0.5974 \\
\hline LDL & 127.3 & 56.9 & 130 & 56.21 & 125.1 & 48.78 & 0.9488 \\
\hline TGs & 154.3 & 88.79 & 168.4 & 101.1 & 205.7 & 103.8 & 0.1538 \\
\hline
\end{tabular}

Fasting blood glucose levels were found to be significantly higher in our NAFLD cases $(P<0.001)$. Recent studies also concluded that impaired glucose tolerance is an independent risk factor for the development of NAFL $\mathrm{D}$ and its progression to NASH [28].

ALT and AST are two of the most reliable markers of hepatocellular injury or necrosis. Previous studies concluded that serum ALT level alone is not predictive of NASH or fibrosis level as ALT can be increased in up to $53 \%$ of NAFLD patients without NASH $[29,30]$. In the present study, both serum ALT and AST levels were found to be significantly higher among NAFLD patients versus normal controls $(P \leq 0.0001)$. However, $48.8 \%$ of our patients had serum hepatic transaminases below the upper limit of normal.

In the present study, 17 patients for whom liver biopsy was performed were further divided by NAS score into two groups, the NASH group (13 patients) and the simple steatosis group (4 patients). No significant relation was found between grades of steatosis and presence or absence of NASH; $38.5 \%$ and $61.5 \%$ of the NASH group had histological evidence of moderate and marked hepatic steatosis, respectively. These results matched with those of previous studies, which identified the degree of steatosis as an independent risk factor for the progression of simple steatosis to NASH [31]. The lack of a statistical significance in our study could be explained by the small number of patients in the biopsy group.

When comparing the results obtained from liver biopsy to CAP in the biopsy group, the degree of steatosis appeared to be the only histological parameter with significant relation. CAP does not seem to be influenced by fibrosis or inflammation which was consistent with the results from previous studies showing that ultrasound attenuation was similar in healthy and cirrhotic patients and much lower than in fatty liver patients [32].

On the other hand, the degree of fibrosis detected histologically in the biopsy group did not appear to be significantly related to that measured using elastography techniques, with comparable results using both Echosens ${ }^{\oplus}$ FibroScan and ARFI. However, this could be explained by the insufficiently small number of patients in the biopsy group. Moreover, the discrepancy appeared among early stages of fibrosis, but not in the more advanced F3 and F4 patients. Previous

Table 6 Distribution of adiponectin rs266729 and rs3774261 genotypes among NAFLD patients and controls

\begin{tabular}{|c|c|c|c|c|c|c|c|}
\hline \multirow{2}{*}{$\begin{array}{l}\text { Adiponectin } \\
\text { variant }\end{array}$} & & \multicolumn{2}{|c|}{ Patients (86) } & \multicolumn{2}{|c|}{ Controls (86) } & \multirow{2}{*}{$\begin{array}{l}\text { OR } \\
(95 \% \mathrm{Cl})\end{array}$} & \multirow[t]{2}{*}{$P$ value } \\
\hline & & $\%$ & Count & $\%$ & Count & & \\
\hline \multirow[t]{5}{*}{ rs266729 } & GG & 5 & 5.8 & 4 & 4.6 & 0.732 & 1.265 (0.362 to 4.239$)$ \\
\hline & CG & 53 & 61.7 & 38 & 44.2 & $0.032^{*}$ & 2.029 (1.097 to 3.665$)$ \\
\hline & CC & 28 & 32.5 & 44 & 51.2 & $0.003^{*}$ & 0.382 (0.205 to 0.719$)$ \\
\hline & Allele G & 63 & 36.6 & 46 & 26.7 & 0.0635 & 1.58 (1 to 2.47$)$ \\
\hline & Allele C & 109 & 63.4 & 126 & 73.3 & 0.0635 & 0.632 (0.404 to 1$)$ \\
\hline \multirow[t]{5}{*}{ rs3774261 } & AA & 11 & $12.80 \%$ & 39 & $45.30 \%$ & $<0.001$ & 0.177 (0.0815 to 0.373 ) \\
\hline & $A G$ & 55 & $63.90 \%$ & 38 & $44.20 \%$ & $0.0093^{*}$ & 2.24 (1.21 to 4.09 ) \\
\hline & GG & 20 & $23.30 \%$ & 9 & $10.50 \%$ & $0.0404^{*}$ & 2.59 (1.09 to 6.42$)$ \\
\hline & Allele A & 77 & $44.80 \%$ & 116 & $67.40 \%$ & $<0.001$ & 0.391 (0.253 to 0.608$)$ \\
\hline & Allele G & 95 & $55.20 \%$ & 56 & $32.60 \%$ & $<0.001$ & 2.56 (1.64 to 3.95$)$ \\
\hline
\end{tabular}


Table 7 Adiponectin rs266729 CG and rs3774261 AG genotypes in relation to the degree of steatosis by CAP, degree of fibrosis by TE, waist circumference, BMI, TGs, and ALT

\begin{tabular}{|c|c|c|c|c|c|c|}
\hline & \multicolumn{3}{|l|}{ rs266729 CG } & \multicolumn{3}{|l|}{ rs3774261 AG } \\
\hline & Yes (53), $N(\%)$ & No (33), $N(\%)$ & $P$ value & Yes (55), $N(\%)$ & No (31), $N(\%)$ & $P$ value \\
\hline \multicolumn{7}{|l|}{ Steatosis } \\
\hline S1 (16) & $8(15.1)$ & $8(24.2)$ & 0.434 & $2(10)$ & $14(21.21)$ & \\
\hline S2 (35) & $24(45.3)$ & $11(33.3)$ & & $12(60)$ & $23(34.85)$ & \\
\hline S3 (35) & 21 (39.6) & $14(42.5)$ & & $6(30)$ & $29(43.9)$ & \\
\hline \multicolumn{7}{|l|}{ FibroScan } \\
\hline F0 (61) & $36(67.9)$ & $25(75.8)$ & 0.469 & $14(70)$ & $47(71.2)$ & 0.9144 \\
\hline F1 (8) & $7(13.2)$ & $1(3)$ & & $2(10)$ & $6(9.1)$ & \\
\hline$F(9)$ & $6(11.3)$ & $3(9.1)$ & & $2(10)$ & $7(10.6)$ & \\
\hline F3 (6) & $2(3.8)$ & $3(9.1)$ & & $2(10)$ & $4(6.1)$ & \\
\hline \multirow[t]{2}{*}{ F4 (2) } & $2(3.8)$ & $1(3)$ & & 0 & $2(3)$ & \\
\hline & Mean \pm SD & Mean \pm SD & & Mean \pm SD & Mean \pm SD & \\
\hline Waist circumference & $108.1 \pm 12.14$ & $106 \pm 10.9$ & 0.4171 & $106.3 \pm 12.24$ & $107.6 \pm 11.5$ & 0.6635 \\
\hline BMI & $34.33 \pm 5.8$ & $32.85 \pm 4.7$ & 0.2237 & $32.68 \pm 4.16$ & $34.09 \pm 5.7$ & 0.3141 \\
\hline Blood pressure & $\begin{array}{l}119 \pm 13 \\
73 \pm 11\end{array}$ & $\begin{array}{l}120 \pm 12 \\
73 \pm 9.4\end{array}$ & 0.71 & $\begin{array}{l}120 \pm 12 \\
73 \pm 10\end{array}$ & $\begin{array}{l}120 \pm 13 \\
72 \pm 10\end{array}$ & 0.78 \\
\hline Fasting glucose & $94 \pm 20$ & $103 \pm 12$ & 0.13 & $100 \pm 32$ & $100 \pm 18$ & 0.2 \\
\hline TGs & $181 \pm 102.9$ & $180.9 \pm 99.9$ & 0.9957 & $171.7 \pm 95.5$ & $183.8 \pm 103.4$ & 0.6433 \\
\hline ALT & $42.85 \pm 31.92$ & $42.33 \pm 27.1$ & 0.9381 & $47.4 \pm 41.5$ & $41.21 \pm 25.76$ & 0.4222 \\
\hline
\end{tabular}

studies have shown that the specificity and sensitivity of FibroScan ${ }^{\circ}$ were highest at $\geq F 4$ [33]. Other studies have validated $\mathrm{TE}$ as a non-invasive mean with high diagnostic accuracy in both identifying and staging of fibrosis in NAFLD patients [34].

In comparison with the gold standard biopsy, CAP can be used for steatosis detection and semi-quantification as it offers several advantages over it, being easy to perform, non-invasive, and inexpensive with immediate results, and has less sampling error [32].

Trans-abdominal ultrasonography is considered an inexpensive non-invasive easy technique for the initial screening of NAFLD with acceptable sensitivity and specificity [35, 36]. CAP had the benefits of being nonoperator-dependent and efficient in the quantification of hepatic steatosis from $10 \%$ and up, and simultaneous assessment of liver fibrosis makes the CAP an alternative method for assessing hepatic steatosis [32]. In the present study, the different grades of brightness detected by trans-abdominal ultrasonography showed a significant correlation with the degree of steatosis measured utilizing CAP $(P<0.001)$.
As regards age and gender, the degree of steatosis detected by CAP showed no significant statistical difference between males and females in our study group and between different age groups. These findings were contradictory with previous studies [37]; the reason could be due to the higher prevalence of females among our study group and that our study group was not representative of all age groups owing to the relatively small number of our study patients.

The gene coding for adiponectin is located on chromosome 3q27 and consists of three exons and two introns, spanning a total of $16 \mathrm{~kb}$ of the genomic sequence. Growing evidence demonstrates the association of single nucleotide polymorphisms (SNPs) of the adiponectin gene with varying levels of circulating adiponectin [9].

SNPs of rs266729 $(-11377 \mathrm{C}>\mathrm{G})$ in the proximal promoter of the adiponectin gene have been widely studied by epidemiological studies. Variant alleles at rs266729, which is associated with lower adiponectin levels, have been shown to be related to obesity, type 2 diabetes (T2DM), and insulin resistance [38, 39].

Table 8 Correlation between liver transaminases and BMI and waist circumference

\begin{tabular}{lllll}
\hline & BMI, $\boldsymbol{P}$ value & Correlation coef. $(\boldsymbol{r})$ & Waist circumference, $\boldsymbol{P}$ value & Correlation coef. $(\boldsymbol{r})$ \\
\hline ALT & 0.38 & 0.095 & 0.086 & 0.18 \\
AST & 0.42 & 0.088 & 0.06 & 0.2 \\
\hline
\end{tabular}


Table 9 Adiponectin genotype and polymorphism, CAP, and metabolic parameters in relation to the degree of obesity

\begin{tabular}{|c|c|c|c|c|c|c|c|}
\hline & $\begin{array}{l}\text { Obese (67), } N \\
\text { (\%) }\end{array}$ & $\begin{array}{l}\text { Non obese (19), } \\
N(\%)\end{array}$ & $\begin{array}{l}P \\
\text { value }\end{array}$ & $\begin{array}{l}\text { Mild (30-34.9), } \mathrm{N}=38, \\
N(\%)\end{array}$ & $\begin{array}{l}\text { Moderate (35-39.9), } N= \\
19, N(\%)\end{array}$ & $\begin{array}{l}\text { Morbid (>40), N=10, } \\
N(\%)\end{array}$ & $\begin{array}{l}P \\
\text { value }\end{array}$ \\
\hline \multicolumn{8}{|l|}{ rs266729 CG } \\
\hline Yes & $44(65.67)$ & $9(47.37)$ & 0.18 & 25 (65.79) & $13(68.42)$ & $4(40)$ & 0.9 \\
\hline No & $23(34.33)$ & $10(52.63)$ & & $13(34.2)$ & $6(31.58)$ & $6(60)$ & \\
\hline \multicolumn{8}{|l|}{ rs3774261 AG } \\
\hline Yes & $44(65.67)$ & $11(57.9)$ & 0.59 & $24(63.16)$ & 14 (73.68) & $6(60)$ & 0.67 \\
\hline No & $23(34.33)$ & $8(42.1)$ & & $14(36.84)$ & $5(26.32)$ & $4(40)$ & \\
\hline \multicolumn{8}{|l|}{ Steatosis } \\
\hline S1 & $8(11.9)$ & $8(42.1)$ & 0.011 & $5(13.16)$ & 3 (15.79) & $0(0)$ & 0.43 \\
\hline S2 & $29(43.3)$ & $6(31.6)$ & & $19(50)$ & $6(31.58)$ & $4(40)$ & \\
\hline \multirow[t]{2}{*}{ S3 } & $30(44.8)$ & $5(26.3)$ & & $14(36.84)$ & $10(52.63)$ & $6(60)$ & \\
\hline & Mean $\pm S D$ & Mean $\pm S D$ & & Mean $\pm S D$ & Mean $\pm S D$ & Mean \pm SD & \\
\hline $\begin{array}{l}\text { Waist } \\
\text { circumference }\end{array}$ & $111 \pm 10$ & $96 \pm 8$ & $\begin{array}{l}< \\
0.0001\end{array}$ & $105 \pm 7.5$ & $114 \pm 8.2$ & $125 \pm 4.6$ & $\begin{array}{l}< \\
0.0001\end{array}$ \\
\hline BMI & $36 \pm 4.7$ & $27 \pm 1.9$ & $\begin{array}{l}< \\
0.0001\end{array}$ & $32 \pm 1.5$ & $37 \pm 1.4$ & $45 \pm 3.6$ & $\begin{array}{l}< \\
0.0001\end{array}$ \\
\hline ALT & $44 \pm 33$ & $38 \pm 19$ & 0.97 & $\begin{array}{l}38 \pm 33 \\
9-180 \\
30\end{array}$ & $\begin{array}{l}53 \pm 31 \\
18-121 \\
45\end{array}$ & $\begin{array}{l}47 \pm 30 \\
8-89 \\
37\end{array}$ & 0.05 \\
\hline TGS & $188 \pm 105$ & $157 \pm 82$ & 0.36 & $167 \pm 100$ & $230+118$ & $185+83$ & 0.16 \\
\hline $\begin{array}{l}\text { Fasting glucose } \\
\text { level }\end{array}$ & $98 \pm 30$ & $95 \pm 23$ & 0.72 & $93 \pm 18$ & $92 \pm 25$ & $127 \pm 53$ & 0.0048 \\
\hline AST & $41 \pm 25$ & $35 \pm 13$ & 0.84 & $37 \pm 26$ & $49 \pm 23$ & $42 \pm 25$ & 0.044 \\
\hline
\end{tabular}

However, to our knowledge, the variants of rs3774261 were not well reported in the Egyptian population. In addition, although studies have examined the association between rs 266729 polymorphisms and the risk of NAFL D [40], no study on the interactions among multiple SNPs in relation to NAFLD risk in the Egyptian population has yet been published.

Studying the prevalence of SNPs at adiponectin rs3774261 in all studied patients and controls showed that all genotypes were statistically significant, where the $\mathrm{G}$ allele was the most frequent among patients (55.2\%) compared to $32.6 \%$ among controls $(P$ value $<0.001)$. This is consistent with the results obtained by [41, 42] who found that the GG genotype in rs3774261 is a risk factor of NAFLD. However, unlike the results obtained from this present study, which showed no significant correlation between any of the rs3774261 variants and the degrees of steatosis or fibrosis detected by CAP and FibroScan Echosens, respectively, nor with any of the significant clinical parameters, their study showed that these variants significantly affected blood glucose and lipid metabolism.

Moreover, analysis of the variant rs266729 showed that the presence of the CG genotype $(P$ value $=0.032)$ and the $C C$ genotype $(P$ value $=0.003)$ was significantly related with the presence of NAFLD. None of them however was significantly related to the degree of steatosis nor fibrosis, or with different clinical parameters such as WC, BMI, TGs, and ALT levels. This is consistent with the results obtained in previous studies where Hsieh et al. [43] found that there was a significant difference in the frequency of adiponectin rs266729 gene polymorphisms between patients with and those without NAFLD.

The relationship between the SNPs of the most significant genotypes was studied and showed no significant relation between the genotypes of rs266729 and those of rs3774261 in the studied NAFLD patients.

Multivariate regression analysis showed no significant correlation with any of the independent risk factors to the degree of steatosis detected by CAP.

\section{Conclusions}

There was an association between polymorphisms of the studied SNPs of rs266729 rs3774261 of the adiponectin gene and NAFLD.

\section{Abbreviations}

NAFLD: Non-alcoholic fatty liver disease; CAP: Controlled attenuation parameter; TE: Transient elastography; LSM: Liver stiffness measurement; SNPs: Single nucleotide polymorphisms; HCV: Hepatitis C virus; HBV: Hepatitis B virus; BMI: Body mass index; IQR: Interquartile range 


\section{Acknowledgements}

Not applicable.

\section{Authors' contributions}

EM and AY did the study design and administrative support. HA did the data collection, assembly, and analysis. RA and ZZ did the literature searches. DS did the SNP analysis. HA and YG did the FibroScan and CAP. ZZ wrote the manuscript. All authors read and approved the final manuscript.

\section{Funding}

No financial or any other support was supplied.

\section{Availability of data and materials}

We have an Excel sheet including the raw data.

\section{Declarations}

\section{Ethics approval and consent to participate}

Not applicable

\section{Consent for publication}

Not applicable

\section{Competing interests}

The authors declare that they have no competing interests.

\section{Author details}

'Department of Endemic Medicine and Hepato-Gastroenterology, Faculty of Medicine, Cairo University, Cairo, Egypt. ${ }^{2}$ Department of Biochemistry, Faculty of Medicine, Cairo University, Cairo, Egypt.

\section{Received: 20 November 2020 Accepted: 28 April 2021}

\section{Published online: 13 May 2021}

\section{References}

1. Koenig AB, Younossi ZM, Abdelatif D, Fazel Y, Henry L, Wymer M (2015) Global epidemiology of non-alcoholic fatty liver disease-meta-analytic assessment of prevalence, incidence and outcomes. Hepatology 64(1):7384. https://doi.org/10.1002/hep.28431

2. Chalasani N, Younossi Z, Lavine JE, Diehl AM, Brunt EM, CusiK CM, Sanyal AJ (2012) The diagnosis and management of non-alcoholic fatty liver disease: practice guideline by the American Association for the Study of Liver Diseases, American College of Gastroenterology, and the American Gastroenterological Association. Hepatology 55(6):2005-2023. https://doi. org/10.1002/hep.25762

3. Almedia NS, Rocha R, Catrin HP, Daltro C (2018) Arthropometric indicators of visceral adiposity as predictors of NAFLD: a review. WJH 10(10):695-701. https://doi.org/10.4254/wjh.v10.i10.695

4. LaBrecque DR, Abbas Z, Anania F, Ferenci P, Khan AG, Goh KL, Hamid SS, Isakov V, Lizarzabal M, Peñaranda MM, Ramos JF, Sarin S, Stimac D, Thomson AB, Umar M, Krabshuis J, LeMair A (2014) World Gastroenterology Organisation Global Guidelines: nonalcoholic fatty liver disease and nonalcoholic steatohepatitis. J Clin Gastroenterol 48(6):467-473. https://doi. org/10.1097/MCG.0000000000000116

5. Festi D, Schiumerini R, Marasco G, Scaioli E, Pasqui F, Colecchia A (2015) Non-invasive diagnostic approach to non-alcoholic fatty liver disease: current evidence and future perspectives. Expert Rev Gastroenterol Hepatol. 9(8):1039-1053. https://doi.org/10.1586/17474124.2015.1049155

6. Seko Y, Yamaguchi K, Itoh Y (2018) The genetic backgrounds in nonalcoholic fatty liver disease. Clinical Journal of Gastroenterology. 11(2): 97-102. https://doi.org/10.1007/s12328-018-0841-9

7. Salman A, Hegazy M, AbdElfadl S (2015) Combined adiponectin deficiency and resistance in obese patients: can it solve part of the puzzle in nonalcoholic steatohepatitis. Open Access Macedonian J Med Sci 3(2):298302. https://doi.org/10.3889/oamjm.057

8. Jamali R, Razavizade M, Arj A, Aarabi MH (2016) Serum adipokines might predict liver histology findings in non-alcoholic fatty liver disease. World Journal of Gastroenterology 22(21):5096-5103. https://doi.org/10.3748/wjg. v22.i21.5096

9. Wei Z, Li-Qun Z, Xiao-Ling H, Jian Q, Guo-Yue Y (2016) Association of adiponectin gene polymorphisms and additional gene-gene interaction with nonalcoholic fatty liver disease in the Chinese Han population. Hepatol Int 10(3):511-517. https://doi.org/10.1007/s12072-015-9687-0

10. https://blogs.worldbank.org/sustainablecities. How do we define cities, towns, and rural areas? (worldbank.org). Accessed 10 Mar 2020

11. Zheng RD, Chen ZR, Chen JN, Lu YH, Chen J (2012) Role of body mass index, waist-to-height and waist-to-hip ratio in prediction of nonalcoholic fatty liver disease. Gastroenterol Res Pract 2012:362147

12. Hernandez-Baixauli J, Quesada-Vazquez S, Marine-Casado R (2020) Detection of early disease risk factors associated with metabolic syndrome: a new era with the NMR metaboloc assessment. Nutrients 12(3):806.

13. Kleiner DE, Brunt EM, Van Natta M, Behling C, Contos MJ, Cummings OW, Ferrell LD, Liu YC, Torbenson MS, Unalp-Arida A (2005) Design and validation of a histological scoring system for nonalcoholic fatty liver disease. Hepatology 41(6):1313-1321. https://doi.org/10.1002/ hep.20701

14. Brunt EM, Kleiner DE, Wilson LA, Belt P, Neuschwander-Tetri BA (2011) Nonalcoholic fatty liver disease (NAFLD) activity score and the histopathologic diagnosis in NAFLD: distinct clinicopathologic meanings. Hepatology 53(3):810-820. https://doi.org/10.1002/hep.24127

15. Chan YH (2003a) Biostatistics102: quantitative data - parametric \& nonparametric tests. Singapore Med J 44(8):391-396

16. Chan YH (2003b) Biostatistics 103: qualitative data -tests of independence. Singapore Med J. 44(10):498-503

17. Dongiovanni P, Petta S, Maglio C, Fracanzani AL, Pipitone R, Mozzi E, Motta BM, Kaminska D, Rametta R, Grimaudo S (2015) Transmembrane 6 superfamily member 2 gene variant disentangles nonalcoholic steatohepatitis from cardiovascular disease. Hepatology 61(2):506-514 https://doi.org/10.1002/hep.27490

18. Wang Z, Xu M, Peng J (2013) Prevalence and associated metabolic factors of fatty liver disease in the elderly. Exp Gerontol 48(8):705-709. https://doi. org/10.1016/j.exger.2013.05.059

19. Summart U, Thinkhamrop B, Chamadol N (2017) Gender differences in the prevalence of nonalcoholic fatty liver disease in the northeast of Thailand: a population-based cross-sectional study [version 2; referees: 2 approved, 1 approved withreservations]. F1000Research 6:1630

20. LazoM HR, Eberhardt MS (2013) Prevalence of nonalcoholic fatty liver disease in the United States: the Third National Health and Nutrition Examination Survey, 1988-1994. Am J Epidemiol 78(1):38-45

21. Lazo M, Clark JM (2008) The epidemiology of nonalcoholic liver disease: aglobal perspective. Semin liver Dis 28(4):339-350

22. Nasr G, Sliem H, Gamal A (2010) Screening for diabetes and cardiovascular risk factors among Egyptian population. Clin Diabetes (Middle East Ed) 9: 127-135

23. Abd Elaziz KM, Gabal MS, Aldafrawy OA, AbouSeif HA, Allam MF (2015) Prevalence of metabolic syndrome and cardiovascular risk factors among voluntary screened middle-aged and elderly Egyptians. J Public Health (Oxf) 37(4):612-617

24. Polyzos SA, Rountouras J, Mantzoras CH Obesity and non-alcoholic fatty liver disease: from pathophysiology to therapeutics. https://doi.org/10.1016/ J.metabol.2018.11.014

25. Hossain N, Afendy A, Stepanova M, Nader F, Srishord M, Rafiq N, Goodman Z, YounossiZ (2009) Independent predictors of fibrosis in patients with nonalcoholic fatty liver disease. Clin Gastroenterol Hepatol 7(11):1224-1229. e2. https://doi.org/10.1016/j.cgh.2009.06.007

26. Caldwell SH, Argo CK (2011) Non-alcoholic fatty liver disease and nutrition. Sherlock's Diseases of the Liver and Biliary System, 12th Edition, vol 28, pp $546-561$

27. El-Koofy NM, Anwar GM, El-Raziky MS, El-Hennawy AM, El-Mougy FM, ElKaraksy HM, Hassanin FM, Helmy HM (2012) The association of metabolic syndrome, insulin resistance and non-alcoholic fatty liver disease in overweight/obese children. Saudi Journal of Gastroenterology: Official Journal of the Saudi Gastroenterology Association. 18(1):44-49. https://doi. org/10.4103/1319-3767.91738

28. Ballestri, S., Lonardo A., Bonapace S., Byrne C.D. Loria P, Targher G (2014) Risk of cardiovascular, cardiac and arrhythmic complications in patients with non-alcoholic fatty liver disease. World I Gastroenterol, 20: 1724-1745, 7, DOl: https://doi.org/10.3748/wjg.v20.i7.1724.

29. Verma S, Jensen D, Hart J, Mohanty SR (2013) Predictive value of ALT levels for non-alcoholic steatohepatitis (NASH) and advanced fibrosis in nonalcoholic fatty liver disease (NAFLD). Liver Int 33(9):1398-1405. https://doi. org/10.1111/liv.12226 
30. Torres DM, Harrison SA (2013) NAFLD: predictive value of ALT levels for NASH and advanced fibrosis. Nat Rev Gastroenterol Hepatol 10(9):510-511. https://doi.org/10.1038/nrgastro.2013.138

31. Fracanzani AL, Valenti L, Bugianesi E, Vanni E, Grieco A, Miele L, Consonni D, Fatta E, Lombardi R, Marchesini G, Fargions (2011) Risk of nonalcoholic steatohepatitis and fibrosis in patients with nonalcoholic fatty liver disease and low visceral adiposity. J Hepatol 54(6):1244-1249. https://doi.org/10.101 6/j.jhep.2010.09.037

32. de Ledinghen V, Vergniol J, Foucher J, Merrouche W, le Bail B (2012) Noninvasive diagnosis of liver steatosis using controlled attenuation parameter (CAP) and transient elastography. Liver Int 32(6):911-918. https:// doi.org/10.1111/j.1478-3231.2012.02820.x

33. Ragazzo TG, Paranagua-Vezozzo D, Lima FR (2017) Accuracy of transient elastography-FibroScan ${ }^{\bullet}$, acoustic radiation force impulse (ARFI) imaging, the enhanced liver fibrosis (ELF) test, APRI, and the FIB-4 index compared with liver biopsy in patients with chronic hepatitis C. Clinics (Sao Paulo) 72(9):516-525. https://doi.org/10.6061/clinics/2017(09)01

34. Wong GL (2013) Update of liver fibrosis and steatosis with transient elastography (FibroScan). Gastroenterol Rep (Oxf) 1(1):19-26. https://doi. org/10.1093/gastro/got007

35. Bohte AE, van Werven JR, Bipat S, Stoker J (2011) The diagnostic accuracy of US, CT, MRI and $1 \mathrm{H}-\mathrm{MRS}$ for the evaluation of hepatic steatosis compared with liver biopsy: a meta-analysis. Eur Radiol. 21(1):87-97. https://doi.org/1 0.1007/s00330-010-1905-5

36. Hernaez R, Lazo M, Bonekamp S, Kamel I, Brancati FL, Guallar E, Clark JM (2011) Diagnostic accuracy and reliability of ultrasonography for the detection of fatty liver: a meta-analysis. Hepatology 54(3):1082-1090. https:// doi.org/10.1002/hep.24452

37. Noureddin M, Yates KP, Vaughn IA, Neuschwander-Tetri BA, Sanyal AJ, McCullough A, Merriman R, Hameed B, Doo E, Kleiner DE, Behling C, Loomba R (2013) Clinical and histological determinants of nonalcoholic steatohepatitis and advanced fibrosis in elderly patients. Hepatology 58(5): 1644-1654. https://doi.org/10.1002/hep.26465

38. Yoshioka K, Hashimoto S, Kawabe N (2014) Measurement of liver stiffness as a non-invasive method for diagnosis of non-alcoholic fatty liver disease. Hepatol Res 45:142-151

39. Tsuzaki K, Kotani K, Sano Y, Fujiwara S, Gazi IF, Elisaf M, Sakane N (2012) The relationship between adiponectin, an adiponectin gene polymorphism, and high-density lipoprotein particle size: from the Mima study. Metabolism 1: $17-21$

40. Zhou YJ, Li YY, Nie YQ (2010) Influence of polygenetic polymorphisms on the susceptibility to non-alcoholic fatty liver disease of Chinese people. $J$ Gastroenterol Hepatol 25(4):772-777. https://doi.org/10.1111/j.1440-1746.2 009.06144.x

41. Ling H, Waterworth DM, Stirnadel HA, Pollin TI, Barter PJ, Kesäniemi YA, Mahley RW, McPherson R, Waeber G, Bersot TP, Cohen JC, Grundy SM, Mooser VE, Mitchell BD (2009) Genome-wide linkage and association analyses to identify genes influencing adiponectin levels: the GEMS Study. Obesity (Silver Spring) 17(4):737-744. https://doi.org/10.1038/oby.2008.625

42. Li HJ, Li CP, Zhang C, Zhong XL, Shi L (2015) Association of adiponectin gene polymorphisms and nonalcoholic fatty liver disease. Int J Clin Exp Med 8(9):16676-16681

43. Hsieh C-J, Wang PW, Hu TH (2015) Association of adiponectin gene polymorphism with nonalcoholic fatty liver disease in Taiwanese patients with type 2 diabetes. PLoS ONE 10(6):e0127521. https://doi.org/10.1371/ journal.pone. 0127521

\section{Publisher's Note}

Springer Nature remains neutral with regard to jurisdictional claims in published maps and institutional affiliations.

\section{Submit your manuscript to a SpringerOpen ${ }^{\circ}$ journal and benefit from:}

- Convenient online submission

- Rigorous peer review

- Open access: articles freely available online

- High visibility within the field

- Retaining the copyright to your article

Submit your next manuscript at $\boldsymbol{\nabla}$ springeropen.com 